Prospek Usaha Agroforestry Karet dan Jernang di Kabupaten Sarolangun - Jambi

(Ardi, Hariadi Kartodihardjo, Dudung Darusman, Bramasto Nugroho)

\title{
PROSPEK USAHA AGROFORESTRY KARET DAN JERNANG DI KABUPATEN SAROLANGUN-JAMBI \\ (Prospects of Rubber and Jernang Agroforestry in the District of Sarolangun- Jambi)
}

\author{
Ardi $^{1)}$ Hariadi Kartodihardjo ${ }^{2)}$ Dudung Darusman ${ }^{2)}$ dan Bramasto Nugroho ${ }^{2)}$ \\ 1) Mahasiswa Program Studi PSL Sekolah Pascasarjana IPB \\ 2) Komisi Pembimbing dan Dosen Sekolah Pascasarjana IPB
}

\begin{abstract}
The research was aims to formulate the feasibility of cultivation in combination of rubber with jernang and minimum area that must be cultivated to meet the needs of decent living for the community. Research located in Lamban Sigatal village at the District Sarolangun in Jambi. Method used is survey method by using questionnaire. The result obtained, based on calculation of the IRR obtained a value of $16.30 \%$ with and interest rate of $15 \%$ this illustrates that the cultivation of rubber and jernang agroforestry worth conducting. In order to meet the needs of decent living for farmers, the cultivation of rubber and jernang agroforestry should at least cultivated area of 1.28 hectares.
\end{abstract}

Keywords: Agroforestry, Rubber, Jernang.

\section{PENDAHULUAN}

Ekosistem hutan harus dipertahankan kualitas dan kuantitas dengan melakukan pengelolaan secara konservasi. Pemanfaatan hutan dilaksanakan dengan mempertimbangkan kelestarian fungsi ekosistem. Pengelolaan hutan yang hanya mempertimbangkan salah satu fungsi saja akan menyebabkan kerusakan hutan.

Tipologi ekosistem hutan di Jambi sangat komplek mulai dari hutan dataran tinggi, hutan dataran rendah, rawa basah/gambut dan mangrove. Hal ini merupakan asset berharga untuk dipertahankan dan dijaga kelestariannya. Upaya yang dilakukan adalah menyeimbangkan antara tujuan konservasi dan peningkatan kesejahteraan masyarakat di sekitar hutan. Hal ini penting karena masyarakat miskin umumnya bermukim di desa-desa sekitar dan dalam hutan. Upaya mempertahankan hutan tanpa memperhatikan kesejahteraan masyarakat di sekitarnya akan sulit dilakukan. Pembalakan liar merupakan salah satu aktivitas masyarakat untuk mendapatkan sumber ekonomi (pendapatan).

Hutan memiliki sumberdaya yang menghasilkan kayu sebagai komoditas pokok, tetapi juga memilik sumberdaya hasil hutan bukan kayu (HHBK) seperti madu, tanaman obat, rotan, hewan buruan, damar, resin dan lainnya. Salah satu tanaman hasil hutan bukan kayu yang dimanfaatkan oleh masyarakat yaitu getah/resin jernang. Produk getah jernang merupakan hasil hutan non kayu dengan nilai ekonomis tinggi. Kondisi saat ini menunjukkan bahwa pengumpulan getah jernang sudah semakin langka. Hal ini disebabkan oleh tidak adanya upaya penanaman kembali (budidaya).

Untuk itu perlu dikembangkan pemanfaatan hasil hutan bukan kayu yang memiliki nilai ekonomis, salah satunya yaitu rotan jernang. Rotan jernang merupakan tanaman yang 
Vol 6, No 1, April 2011: $10-14$

dimanfaatkan oleh masyarakat Jambi sejak zaman dahulu. Resin/getah jernang dapat menjadi sumber pendapatan masyarakat karena memiliki nilai ekonomis dan ada pangsa pasarnya. Jika selama ini rotan jernang di manfaatkan oleh masyarakat dengan jalan mencari/memanen di dalam hutan, seiring semakin berkurangnya tutupan hutan dan kelangkaan tanaman jernang di Sarolangun, maka di masyarakat mulai muncul inisiasi untuk membudidayakan dan menanam tanaman jernang di dalam kebun-kebun karet masyarakat atau yang biasa di sebut dengan pola agroforestry, karena agroforestry karet telah umum dilakukan oleh masyarakat Jambi (Rasnovi 2006).

Penelitian ini bertujuan untuk mengetahui : (1) kelayakan usaha budidaya jernang yang dikombinasikan dengan tanaman karet. (2) luasan minimal yang harus dibudidayakan untuk memenuhi kebutuhan hidup layak bagi masyarakat.

\section{METODE PENELITIAN}

Penelitian ini dilakukan dengan menggunakan metode survey lapangan. Data yang dikumpulkan mencakup data primer dan sekunder. Data primer diambil melalui wawancara secara langsung dengan bantuan daftar pertanyaan yang telah dipersiapkan (Bungin 2007). Sampel diambil dari seluruh masyarakat pengumpul jernang yang terdapat di desa yaitu sebanyak 51 orang. Sedangkan data sekunder dilakukan dengan teknik dokumentasi yang diperoleh dari berbagai laporan.

Penentuan lokasi dilakukan secara sengaja (purposive sampling) yaitu di Desa Lamban Sigatal Kecamatan Pauh Kabupaten Sarolangun Propinsi Jambi. Pemilihan lokasi ini dikarenakan pada desa ini banyak terdapat produksi jernang dan akan dijadikan daerah sentra produksi jernang.

Analisis kelayakan agroforestry jernang dan karet menggunakan analisis usaha tani. Menurut Soekartawi (1995), penerimaan usaha tani adalah perkalian antara produksi yang diperoleh dengan harga jual. Analisis dilakukan pada dua jenis tanaman (jernang dan karet), sehingga formula yang digunakan adalah:

$$
\mathrm{TR}=\sum_{i=1}^{n} \mathrm{Y} . \mathrm{Py}
$$

Keterangan: $\mathrm{TR}=$ Total penerimaan

$\mathrm{Y} \quad=$ Produksi yang diperoleh dalam suatu usahatani

Py $=$ Harga $Y$

Untuk perhitungan kelayakan usaha maka digunakan perhitungan tingkat pengembalian internal (IRR). Menurut Soekartawi (1995) tingkat pengembalian internal (IRR) merupakan parameter yang dipakai apakah suatu usahatani mempunyai kelayakan usaha atau tidak. Kriteria layak atau tidak layak bagi usahatani bila IRR lebih besar dari tingkat bunga yang berlaku saat usahatani itu di usahakan dengan meminjam uang (biaya) dari 
bank pada saat nilai neto sekarang (net present value, NPV $=0$ ). Oleh karena itu untuk menghitun IRR diperlukan nilai NPV terlebih dahulu. NPV dihitung dengan rumus:

$$
\operatorname{TR}=\sum_{\substack{\mathrm{n} \\ \mathrm{i}=1}}^{\mathrm{B}-\mathrm{C}) /(1+\mathrm{i})^{\mathrm{t}}}
$$

dan perhitungan IRR menggunakan rumus :

$\operatorname{IRR}=\mathrm{i}_{\mathrm{t}}+\left(1-\mathrm{i}_{\mathrm{t}}\right)\left\{P \mathrm{~V}_{(+)} / \mathrm{PV}_{\mathrm{t}}+\mathrm{PV}_{(-)}\right\}$

Keterangan: $\mathrm{n}$ = banyak kegiatan

$\mathrm{t} \quad=$ waktu

B = benefit (manfaat)

$\mathrm{C}=$ cost (biaya)

$\mathrm{i} \quad=$ tingkat bunga yang berlaku

$\mathrm{PV}_{(+)}=$nilai sekarang positif

$\mathrm{PV}_{(-)} \quad=$ nilai sekarang negatif

Penilaian kelayakan dilihat dari prospek usaha agroforestry karet dan jernang dalam memenuhi kebutuhan hidup minimum (KHM) dan kebutuhan hidup layak (KHL) tahunan pekebun. Menurut Sinukaban (2007) $\mathrm{KHL}$ adalah $250 \% \mathrm{KHM}$ dan $\mathrm{KHM}=320 \mathrm{x}$ harga beras $\mathrm{kg}^{-1} \mathrm{x}$ jumlah anggota keluarga (5 orang) (Sajogyo, 1977). Selanjutnya analisis luasan lahan minimum usaha perkebunan (UP) minimum (Lmin), agar memenuhi KHL yaitu Lmin dibagi dengan pendapatan bersih $(\mathrm{Pb})$ atau dengan persamaan : $\mathrm{L} \min =\mathrm{KHL} \mathrm{Pb}^{-1}$ (Monde, 2008).

\section{HASIL DAN PEMBAHASAN}

Pengusahaan budidaya karet telah lama dilakukan oleh masyarakat di Desa Lamban Sigatal Sarolangun, Jambi. Selain itu dari pemanfataan hasil hutan di lakukan juga pemanfaatan jernang. Hingga saat ini pengumpulan jernang dari hutan oleh masyarakat tetapi hasil yang didapatkan sudah tidak begitu banyak. Oleh karenanya muncul inisiasi dari masyarakat untuk dapat membudidayakan rotan jernang sebagai penghasil jernang. Tanaman rotan jernang adalah tanaman yang memerlukan tanaman inang sebagai tanaman rambatannya (Sumarna 2004). Tanaman inang jernang adalah tanaman yang berkayu sehingga usaha untuk mengkombinasikan tanaman karet dengan tanaman rotan jernang.

Oleh karena budidaya tanaman karet dan rotan jernang jernang ini belum ada yang mengusahakannya, maka inisiasi masyarakat untuk pengembangan ini dilakukan perhitungan dengan asumsi dari kebiasaan masyarakat dan hasil atau produksi yang didapatkan masyarakat dari hutan.

Hasil analisis menunjukkan, apabila $1 \mathrm{Ha}$ lahan budidaya tanaman jernang dan tanaman karet sebagai inang dengan jarak tanam $3 \mathrm{~m} \times 7 \mathrm{~m}$, didapatkan komposisi 420 batang tanaman karet dan 390 rumpun tanaman jernang (Gambar 1). Pada awal panen 
Vol 6, No 1, April 2011: 10 - 14

(tahun ke-5), tanaman karet akan memproduksi getah sebanyak $500 \mathrm{~kg} / \mathrm{Ha}$ dan $1000 \mathrm{~kg} / \mathrm{Ha}$ pada panen berikutnya hingga peremajaan pada tahun ke-30 (kayunya dijual).

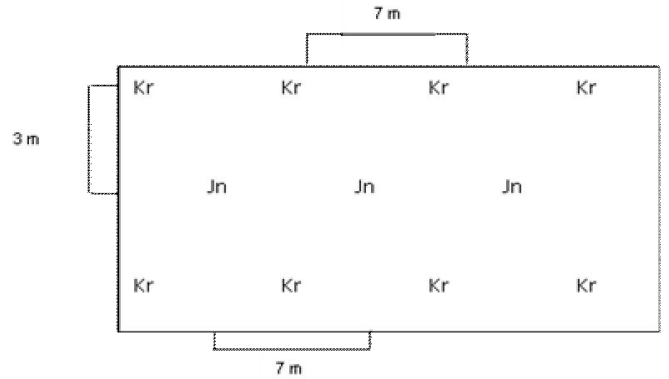

Gambar 1. Komposisi budidaya tanaman karet dan jernang.

Pada panen perdana (tahun ke-8) tanaman rotan jernang menghasilkan getah jernang sebanyak $59 \mathrm{~kg}$ dan prediksi sebanyak $117 \mathrm{~kg} / \mathrm{ha}$ pada tahun $\mathrm{ke} 12$ dan seterusnya hingga periode produktif 30 tahun. Dengan harga jernang yang berlaku di tingkat pengolah jernang adalah sebesar Rp 400.000/kg saat penelitian, penghasilan yang akan diterima di tahun ke 8 adalah Rp 23,4 juta/hektar/tahun atau Rp 1,95 juta/hektar/bulan. Pada panen berikutnya adalah sebesar Rp 46,8 juta/hektar/tahun atau sekitar Rp 3,9 juta/hektar/bulan.

Berdasarkan hasil analisis kelayakan usaha budidaya jernang dan karet diperoleh NVP df $15 \%$ sebesar Rp. 21,858,461 serta IRR sebesar 16,30\%. Menurut Soekartawi (1995) apabila IRR lebih besar dari nilai tingkat bunga yang berlaku maka usahatani layak untuk diusahakan. Dengan demikian budidaya jernang secara finansial layak untuk diusahakan karena nilai IRR $16,30 \%$ > dari tingkat bunga $15 \%$.

Kebutuhan hidup layaknya (KHL) petani (dengan jumlah KK 5 orang) didesa Lamban Sigatal adalah sebesar Rp. 28,000,000,-. Kebutuhan hidup layak (KHL) masyarakat disekitar hutan di Desa Lamban Sigatal selengkapnya tertera pada Tabel 1.

Tabel 1. Kebutuhan hidup layak (KHL) masyarakat disekitar hutan ${ }^{1)}$

\begin{tabular}{|l|c|c|c|c|c|c|}
\hline $\begin{array}{c}\text { Jenis } \\
\text { Pengeluaran }\end{array}$ & $\%$ & $\begin{array}{c}\mathrm{Kg} \\
\text { Bera } \\
\mathrm{s}\end{array}$ & $\begin{array}{c}\text { Harga } \\
\text { Beras (Rp } \\
\left.\mathrm{kg}^{-1}\right)^{2)}\end{array}$ & $\begin{array}{c}\text { Pengeluaran } \\
\left(\mathrm{Rp}_{\text {orang }}^{-1} \text { th }^{-}\right. \\
1)\end{array}$ & $\begin{array}{c}\text { Jumlah } \\
\text { Keluarga }^{3)}\end{array}$ & $\begin{array}{c}\text { Kebutuhan } \\
\left(\mathrm{Rp} \mathrm{KK}^{-1} \text { th }^{-}\right. \\
1)\end{array}$ \\
\hline $\mathrm{KFM}^{4)}$ & 100 & 320 & 7.000 & 2.240 .000 & 5 & 11.200 .000 \\
\hline Pendidikan & 50 & 160 & 7.000 & 1.120 .000 & 5 & 5.600 .000 \\
\hline Kesehatan & 50 & 160 & 7.000 & 1.120 .000 & 5 & 5.600 .000 \\
\hline $\begin{array}{l}\text { Sosial/Tabunga } \\
\mathrm{n}\end{array}$ & 50 & 160 & 7.000 & 1.120 .000 & 5 & 5.600 .000 \\
\hline \multicolumn{1}{|c|}{$\mathrm{KHL}^{5)}$} & & & & 5.600 .000 & & 28.000 .000 \\
\hline
\end{tabular}

Sumber : Hasil Survey (diolah)

1) dimodifikasi dari Monde (2008)

2) rata-rata harga beras di Kabupaten Sorolangun pada saat penelitian

3) diasumsikan jumlah anggota keluarga 5 orang

4) KFM (Kebutuhan Fisik Minimum)

5) KLH (Kebutuhan Hidup Layak) 
Berdasarkan perhitungan pendapatan yang akan diterima dari perhitungan NPV maka untuk dapat memenuhi kebutuhan hidup layak, petani harus melakukan usaha budidaya Jernang dan karet setidaknya seluas 1,28 hektar/KK. Mengacu kepada pendapat Soekartawi dan Sinukaban maka usaha budidaya agroforestry karet dan jernang layak untuk diusahakan dan dapat memenuhi kebutuhan ekonomi masyarakat.

\section{KESIMPULAN}

1. Usaha agroforestry jernang dan karet layak untuk diusahakan secara finansial.

2. Untuk dapat memenuhi kebutuhan hidup layak bagi petani maka usaha agroforestry karet dan jernang harus diusahakan dengan luas minimal 1,28 hektar.

\section{DAFTAR PUSTAKA}

Bungin B. 2007. Penelitian Kualitatif. Komunikasi, Ekonomi, Kebijakan Publik, dan IImu Sosial Lainnya. Jakarta: Kencana Prenada Media Group.

Monde A. 2008. Dinamika Kualitas Tanah, Erosi dan Pendapatan Petani Akibat Alih Funsi Lahan Menjadi Lahan Pertanian dan Agroforestry Kakao di DAS Nompu Sulawesi Tengah. Disertasi Pascasarjana IPB.

Rasnovi S. 2006. Ekologi Regenerasi Tumbuhan Berkayu Pada Sistem Agroforest Karet. Bogor: Disertasi. Tidak dipublikasi.

Sajogjo. 1977. Garis Miskin dan Kebutuhan Pangan. Lembaga Penelitian Sosiologi Pedesaan (LPSP). Bogor: IPB Press.

Soekartawi. 1995. Analisis Usahatani. Jakarta: Penerbit Universitas Indonesia.

Sumarna Y. 2004. Budidaya Rotan Penghasil Getah Jernang. Makalah pada Pelatihan Budidaya Rotan Jernang November 2004 di Jambi. 